\title{
A Study on the Use of Composite Materials in Contemporary Sculptures in China
}

\author{
Hongwu Li $i^{1, a}$ \\ ${ }^{1}$ Department of sculpture, Academy of Fine Arts, Zhengzhou University Zhengzhou, China 450000 \\ a625526223@qq.com
}

Keywords: contemporary sculpture in China; composite materials; use.

Abstract. Composite material sculptures refer to sculptures made of two or more materials. Composite material sculptures came into vogue in China since the 1990s and broke the limitations of traditional sculpture forms. The use of a variety of sculpture materials makes sculptures more gorgeous and colorful. It gives full play to the properties of all kinds of materials, highlights the characteristics of sculptures and gives people different aesthetic experience. For this end, this article attempts to discuss the use of composite materials in contemporary sculpture in China.

\section{Introduction}

With the progress of times and development of technology, more and more materials are available for sculpture art. The development of material casting process provides more abundant presentation forms for sculpture art and makes materials more fully and skillfully used in sculpture art. Composite materials have been widely used in contemporary sculpture. The choice of materials has an important influence on the presentation effect of sculptures. Sculptures are not only a presentation process of artistic images, but also a change process of material forms. Besides, the presentation effect of sculptures is subject to the limit of materials. Only when right materials are selected, will the connotations of sculptures be expressed more fully and sculptures have higher ornamental and artistic values. The use of composite materials can mix the texture, touch and ornamental effect of different materials in sculptures make the sculpture more expressive.

\section{The Influence of the Use of Composite Materials on Sculpture Art in China}

Substance materials are one of the main differences between sculpture and other artistic expression forms. The properties of materials are an important part of the artistic aesthetics of sculptures. In the long development of sculpture art, sculpture materials in every era reflect characteristics of their times. Ancient people mainly adopt wood, bones and stones as sculpture materials. With the genesis of ceramic technology, colored pottery and colored sculpture develop rapidly. Composite materials have been applied in an early time. The bronze cultural relic, Sanxingdui Portrait, unearthed in Sanxingdui, Guanghan City, Sichuan Province, is exactly a composite material sculpture, with bronze and precious metal as main materials. With the improvement of public welfare technology, iron materials began to be applied in sculptures since the Song Dynasty and achieved an entirely different presentation effect from copper sculptures. Till the Yuan, Ming and Qing Dynasties, sculpture materials were increasingly abundant. A lot of precious materials were applied to sculptures, such as ivory, crystal, agate, azure stone, mussel, and so on. Main sculpture materials in different historical periods are shown in Table 1. Since the 20th Century, traditional Chinese culture has been subject to a huge impact from western culture. Western sculpture art spread into China and had a profound influence on traditional sculpture art in China. Gradually, sculpture art began to diversify [1]. 
Table 1 Historical Development of Sculpture Materials

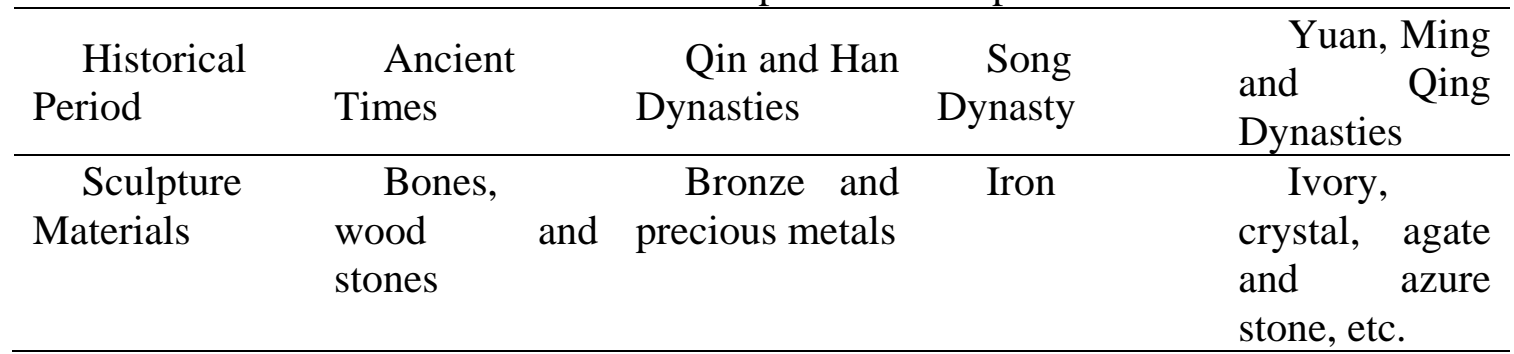

However, contemporary sculpture artistic creation doesn't exclude traditional materials. Traditional materials and traditional sculpture techniques are an integral part of the contemporary diversified creation context and make expression forms of contemporary sculptures richer and more colorful. The main characteristic is that the choices of materials are expended. The processing level of materials continues to rise. The application of materials becomes more flexible, breaks the limitations of traditional usage of materials, allows sculptures to make full use of the properties of materials and highlights the artistic characteristics of works and enriches the connotations of creation. Although there is no distinction between good or bad for traditional and modern materials, they have great discrepancies in physical properties and contemporary significance. During the creation of sculptures, only when suitable materials are selected, will the characteristics and artistic value of materials be embodied. At present, composite material sculptures have been widely recognized by sculpture lovers and collectors and widely used in contemporary sculpture creation. Some landscape designs and square sculptures also apply numerous composite materials. A comparison between traditional sculpture art and contemporary sculpture art is shown in Table 2 [2].

Table 2 A Comparison Between Traditional Sculpture Art and Contemporary Sculpture Art

\begin{tabular}{ll}
\hline Traditional Sculpture Art & Contemporary Sculpture Art \\
\hline Realism & Abstractionism \\
Single material & Composite materials \\
Single expression form & Diversified expression forms \\
\hline
\end{tabular}

\section{Ornamental Effect of Composite Material Sculptures}

Sculptures made of different materials can bring different sensory experience to people. Their shape, color and touch, etc. will arouse different psychological reactions among people. With respect to the shape, straight and curved lines bring completely different feelings to people. Sculptures made of straight line materials give people a nervous and solemn feeling. While curved line materials can give people a relaxed and soft feeling. In physiology, this is because when people observe sculptures, if their eyeballs have rectilinear motions along lines, the ocular muscles will develop a sense of tension. While when having curvilinear motions, their eyeballs will be relaxed slowly. A comparison between visual reactions of people to lines is shown in Table 3 [3].

Table 3 A Comparison Between Visual Reactions to Lines

\begin{tabular}{cll}
\hline Line & Straight Line & Curved Line \\
\hline Visual Reaction & Nervous and solemn & Relaxed and soft \\
& Dull and boring, etc. & $\begin{array}{l}\text { Flexible and satisfied, } \\
\text { etc. }\end{array}$ \\
\hline
\end{tabular}

So sculptures made of straight and curved line materials give people completely different visual experience. The use of composite materials can soften properties of these materials and make people gain a comfortable aesthetic experience. Again, different geometries will give people different psychological hints. For example, when people see a triangle structure, they will develop a sense of firmness. This is because a triangle is stable. Using the presentation effect of different geometries, we 
can make sculptures achieve expected effect of the creators. Fig. 1 shows a metal composite material sculpture, Sudden Rain, and mainly uses straight lines to represent the abruptness of rain. Ripples of rain falling to the ground can offset a feeling of tear of the sudden rain and make people feel the suddenness of rain, instead of uncomfortable [4].

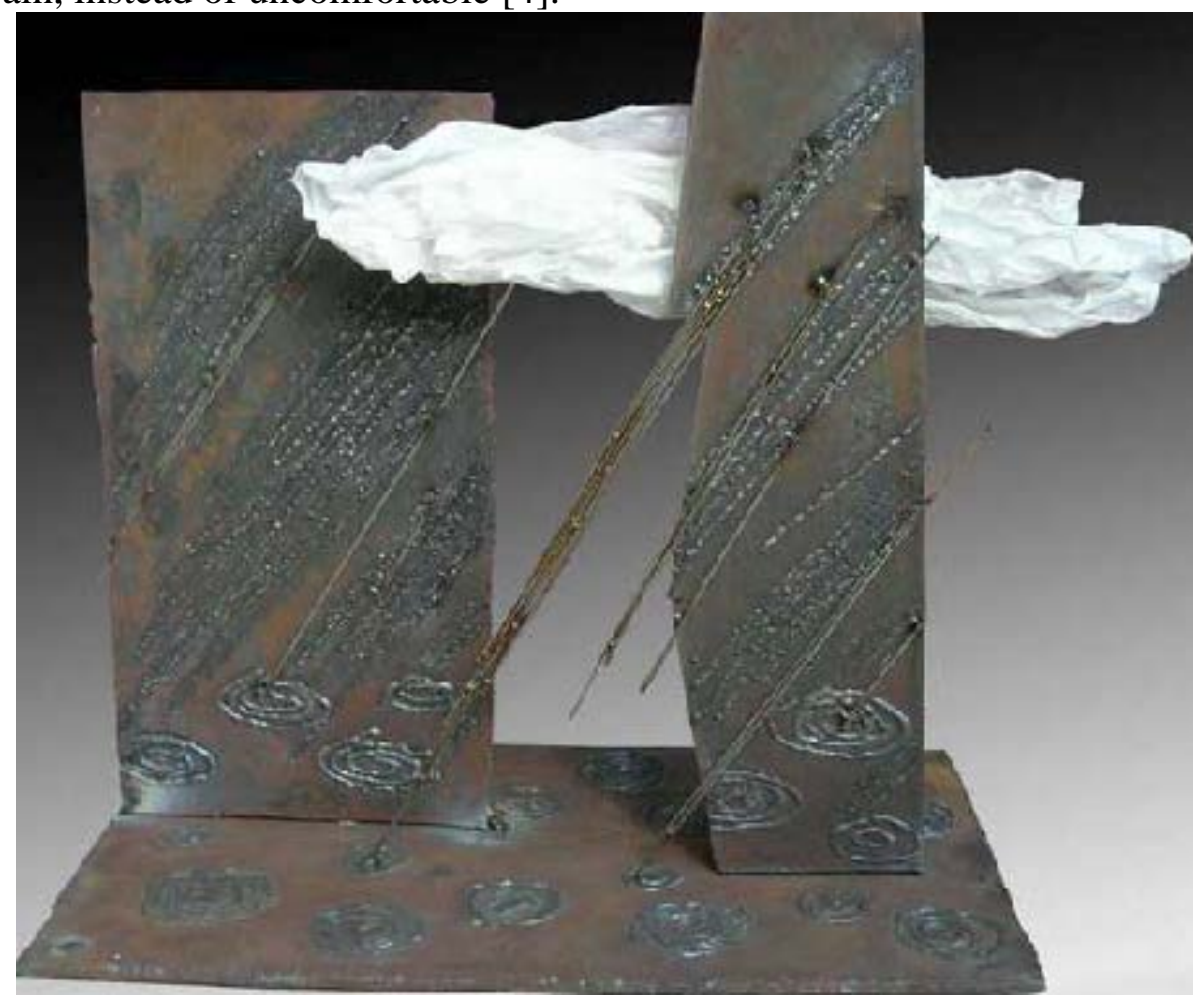

Fig. 1 A Metal Composite Material Sculpture- Sudden Rain

\section{The Prospect of the Application of Composite Materials in Sculpture Creation}

The rich visual effect of composite material sculptures is a main research topic that current sculptors are willing to explore. The application of composite materials in contemporary sculptures changes people's aesthetic habits for traditional sculptures, affects the artistic concept that people have formed in the long historical process from bottom to top and eventually wins unanimous recognition and wide respect from artists and collectors. The application of composite materials and diversified development of sculpture art are in line with people's multiple demands for artistic aesthetics. They are a result of mutual selection between men and culture. Through different physical forms, sculpture art conveys increasingly strong meanings of life, stimulates people to get close to nature and revives their inner self. The application of composite materials in sculpture creation will continue to improve the expressive and infective power of sculptures and give full play to sculpture artist's imagination [5].

Although it is a short time since composite material sculptures came in vogue in China, it has boomed like a prairie fire within more than twenty years and caused a huge impact on traditional sculpture art. The application and development of composite materials in sculpture creation will inevitably be affected by some conservative ideas. Sculpture artists must innovate boldly, fully exploit the use of all kinds of materials, make their application in sculptures improve the presentation effect of sculptures to a greater extent and accepted by more people.

\section{Conclusion}

To sum up, composite materials have a profound influence on contemporary sculpture art in China. Their application in sculpture art can largely enrich the expression form of sculptures, deepen artistic connotations and let them have stronger appeal and artistic value. 


\section{References:}

[1]Cone L. Material Matters: The Conservation of Modern Sculpture[J]. Studies in Conservation, 2003, 41(2):93.

[2]Rödlach A. Popular Images of the AIDS Epidemic: Contemporary Wood Sculptures from Southern Zimbabwe[J]. African Arts, 2010, 43(2):54-67.

[3]Harle R. The Human Factor: The Figure in Contemporary Sculpture ed. by Ralph Rugoff (review)[J]. Leonardo, 2015, 48(2):201-202.

[4]Naginski E. The Blind Spot: An Essay on the Relations between Painting and Sculpture in the Modern Age, by JACQUELINE LICHTENSTEIN; Chris Miller[J]. The British Journal of Aesthetics, 2013, 53(4):479-482.

[5]Millard C W. The Reclining Figure and the Development of Modern Sculpture[J]. Hudson Review, 1974, 27(2):234-244. 